\title{
El blog como un recurso educativo para el fortalecimiento del proceso lector en estudiantes sordos*
}

| Fecha de recibido: 21 de junio del 2021 | Fecha de aprobación: 12 de septiembre del 2021 |

\section{Liliana Beatriz Herrera Nieves}

Doctora en Ciencias de la Educación

Docente, Universidad del Atlántico Colombia

Rol de la investigadora: teórico y escritura https://orcid.org/0000-0002-6578-4964

$\bowtie$ lilianaherrera@mail.uniatlantico.edu.co

\author{
Osmeris Esquea Gamero \\ Magíster en Educación \\ Docente, Universidad del Atlántico \\ Colombia \\ Rol de la investigadora: teórico y escritura \\ https://orcid.org/0000-0001-9379-1953 \\ $\bowtie$ osmerisesquea@mail.uniatlantico.edu.co
}

\section{Carmen Alicia de la Cruz Ruiz}

Licenciada en Educación Especial

Colombia

Rol de la investigadora: experimental y escritura

https://orcid.org/0000-0002-3576-2270

$\triangle$ carmendelacruz2096@gmail.com

\section{Astrid Katerine Serje Payán}

Licenciada en Educación Especial

Colombia

Rol de la investigadora: experimental y escritura https://orcid.org/0000-0002-8657-6574 $\triangle$ Serjekaterin@gmail.com

\section{Nedis Johana Barros Ballesteros}

Licenciada en Educación Especial Colombia

Rol de la investigadora: experimental y escritura https://orcid.org/0000-0002-5556-6525 \njohana25@gmail.com

* Artículo de investigación desarrollado en la Universidad del Atlántico y adscrito al grupo de investigación en Tecnologías de la Información y Comunicación y Gestión del Conocimiento, Enl@ce.

Cómo citar este artículo: Herrera-Nieves, L. B., Esquea-Gamero, O., Serje-Payán, A. K., De la Cruz-Ruiz, C. A.,

\& Barros-Ballesteros, N. J. (2021). El blog como un recurso educativo para el fortalecimiento del proceso lector en estudiantes sordos. Ciencia y Poder Aéreo, 16(2), 148-162. https://doi.org/10.18667/cienciaypoderaereo.718 


\section{El blog como un recurso educativo para el fortalecimiento del proceso lector en estudiantes sordos}

\section{Blogging as an Educational Resource for Strengthening the Reading Process by Deaf Students}

Resumen: El proceso lector, entendido como el desarrollo de todas aquellas actividades básicas y fundamentales para poder decodificar, inferir, interpretar y valorar los mensajes escritos, es fundamental para la comunicación. Para los estudiantes sordos se constituye en una habilidad muy importante que les permite comunicarse con sus pares oyentes y acceder al conocimiento. En el estudio se analizó el blog como recurso formativo que apoya el proceso de comprensión lectora en estudiantes sordos de grado noveno de una institución educativa distrital de Barranquilla. En el marco de un enfoque cualitativo de corte histórico hermenéutico, se contó con la participación de estudiantes sordos y docentes para realizar un diagnóstico. Los resultados demuestran las dificultades de los estudiantes sordos en cuanto a la comprensión lectora y la importancia del uso de recursos mediados por tecnologías y multimedia en la motivación y aprendizaje de la lectura. A partir de este diagnóstico se elaboró una propuesta tecnopedagógica consolidada en un blog, el cual fue valorado por jueces expertos y mediante una prueba piloto, lo que propició una versión 2.0. Se sugiere su implementación y estudios futuros.

Palabras clave: lectura; lengua de señas; sordera; tecnología educativa.

Abstract: The reading process, understood as the development of all the basic and fundamental activities to be able to decode, infer, interpret and value written messages, is essential for communication. For deaf students, reading is a very important skill that allows them to communicate with their hearing peers and access knowledge. Faced with this, the study addressed blogging as a training resource that supports the reading comprehension process in ninthgrade deaf students at a district educational institution in Barranquilla (Colombia). Framed within a qualitative approach to historical hermeneutics, a group of deaf students and their teachers participated in a diagnosis study. The results show the difficulties of these students in reading comprehension, as well as the importance of the use of resources driven by technologies and multimedia for motivating students towards reading. Based on the diagnosis, a techno-pedagogical proposal was elaborated and consolidated in a blog, which was later evaluated by expert judges and through a pilot test, leading to a 2.0 version whose implementation is suggested in future studies.

Keywords: reading; sign language; deafness; educational technology.

Resumo: O processo de leitura, entendido como o desenvolvimento de todas as atividades básicas e fundamentais para poder decodificar, inferir, interpretar e valorizar as mensagens escritas, é fundamental para a comunicação. Para alunos surdos, é uma habilidade muito importante que lhes permite se comunicar com seus colegas ouvintes e acessar o conhecimento. No estudo, o blog foi analisado como recurso formativo que subsidia o processo de compreensão leitora de alunos surdos do nono ano de uma instituição municipal de ensino de Barranquilla. No âmbito de uma abordagem qualitativa de corte histórico-hermenêutico, alunos e professores surdos participaram para a realização de um diagnóstico. Os resultados demonstram as dificuldades dos alunos surdos em termos de compreensão leitora e a importância do uso de recursos mediados por tecnologias e multimídia na motivação e aprendizagem da leitura. A partir desse diagnóstico, foi desenvolvida uma proposta técnico-pedagógica consolidada em um blog, a qual foi avaliada por juízes especialistas e por meio de um teste piloto, que resultou na versão 2.0. Sugere-se sua implantação e estudos futuros.

Palavras-chave: leitura; linguagem de sinais; surdez; tecnologia educativa. 
Las competencias lingüísticas hacen parte de las exigencias en el sistema educativo colombiano. Además de ello, forman el conjunto de conocimientos que permiten la comprensión y producción de discursos correctos. Su importancia recae en que favorecen la expresión y adquisición de la información escrita, por lo tanto, las personas que tienen dificultades en la lectura y escritura no solo se ven afectadas en su rendimiento académico (Hernández-Sánchez \& Santamaría-Sancho, 2016), sino también en su adaptación al ámbito sociocultural y futuro campo laboral. En el caso de las personas sordas, según Augusto y De Antoñana (2002), "la lectura no alcanza un nivel funcional antes del final del $4 .^{\circ}$ año de escolarización. El $80 \%$ de los adolescentes sordos son analfabetos, y la fuente principal de estas dificultades es de origen lingüístico" (p. 183). Es reducido el número de estudiantes sordos que logra un nivel de lectura que les permita acceder a la universidad y, consecuentemente, a posiciones laborales y sociales que hubieran estado a su alcance de no ser por estos problemas (Alegría et al., 2009). En una investigación realizada por González y Domínguez (2019), en la que se hizo un estudio de tipo comparativo entre el nivel de comprensión lectora de estudiantes sordos con y sin implante coclear, se demostró que los niveles de lectura de los niños sordos están supeditados a su capacidad fonológica. En ese sentido, los implantes cocleares cumplen un papel decisivo, ya que promueven mejores resultados en todas las actividades prácticas, por lo cual el rendimiento lector evidencia la condición de su capacidad fonológica. De igual manera, Mendoza y Jackson-Maldonado (2020) encontraron que existe un efecto de facilitación e interferencia al activar la lengua de señas en un estudio que tuvo como objetivo identificar si los sordos signantes activan la capacidad fonológica en la lectura de palabras escritas en español.

Las personas sordas tienen lagunas lingüísticas importantes, por lo cual presentan dificultades en el dominio de su segunda lengua, en este caso, el castellano escrito. Los principales obstáculos lingüísticos que tienen se refieren a habilidades fonológicas pobres, las cuales, en caso de que las desarrollen, lo hacen a un ritmo distinto que los lectores oyentes (Greene-Woods
\& Delgado, 2020). Lo anterior obedece a sus problemas en el desarrollo lingüístico y las dificultades que han afectado su adecuado proceso cognitivo y simbólico, bases fundamentales para el desarrollo del lenguaje escrito, y cualitativamente diferente a la lengua de señas, que se constituye en su primera lengua y, por ende, la utilizan para acceder a los conceptos básicos y para comunicarse (Carrero, 2017).

Comprender la realidad de los estudiantes sordos implica reconocer la diversidad y proveer espacios educativos que admitan sus diferencias o similitudes culturales y la variación lingüística (Herrera \& Calderón, 2019). Los estudiantes con discapacidad auditiva procesan la información a través de su canal visual, por lo tanto, es necesario que el docente utilice recursos visuales para la enseñanza de, principalmente, conceptos abstractos. Asimismo, se debe garantizar la comunicación mediante el uso de lengua de señas, gestos corporales, expresiones faciales y la lectura labiofacial (Al-Ibrahim, 2019). Para lograr que los estudiantes sordos progresen académicamente, deben seleccionarse las estrategias educativas adecuadas y los enfoques deben cambiar para adaptarse a las diversas necesidades de los estudiantes (Greene-Woods \& Delgado, 2020).

En datos reportados por el Ministerio de Salud y Protección Social respecto a la formación educativa de la población sorda colombiana, se evidencia que el $36 \%$ no alcanzó ningún nivel educativo, el $43 \%$ culminó la primaria, el $16 \%$ la secundaria y tan solo el $3 \%$ accedió a un nivel educativo superior o universitario (INSOR, 2019). De acuerdo al Boletín Territorial del departamento del Atlántico, cerca del $41 \%$ del total de sordos son analfabetas (INSOR, 2015). Lo anterior sugiere la importancia de reflexionar acerca del proceso de enseñanza-aprendizaje de la lectura de los estudiantes sordos; un camino que resignifique las estrategias pedagógicas mediante la incorporación de elementos como la tecnología para favorecer las competencias comunicativas y la participación, progreso e inclusión en el ámbito social y laboral de las personas con discapacidad auditiva. Innovar en las prácticas educativas de estudiantes sordos significa que los docentes deben asumir un papel activo, en el que deben adecuar 
la situación y contenidos de aprendizaje de acuerdo a las necesidades de los estudiantes y considerar la variación comunicativa (Herrera \& Calderón, 2019).

En el contexto donde se llevó a cabo el presente estudio, se identificó que los estudiantes sordos son usuarios fluidos de Lengua de Señas Colombiana (LSC) y la utilizan como medio de comunicación en diferentes escenarios. Sin embargo, se identificaron dificultades en el proceso lector, específicamente en sus habilidades fonológicas, reconocimiento léxico, competencias gramaticales, variedad de vocabulario, capacidad de realizar cierres inferenciales y capacidades metacognitivas. La mayoría de los estudiantes sordos presentan dificultades en la decodificación de las palabras escritas por realizar lectura fragmentada, principalmente al encontrar vocabulario nuevo (Martínez, 2021). Por lo anterior, la investigación centra su objeto de estudio a través de la siguiente pregunta: ¿qué tipo de recursos educativos fortalecen el proceso lector en los estudiantes sordos?

Dentro de la problemática observada en este estudio hay un factor a considerar: la extraedad, entendida como el desfase entre la edad del estudiante y el grado académico (MEN, s. f.). Esto se evidencia al encontrar estudiantes del grado noveno con edades entre los 17 y los 40 años, muy por encima de la edad establecida para ese grado escolar. La extraedad puede asociarse con el ingreso tardío al sistema educativo, la deserción escolar, los cambios de domicilio, la precaria situación económica de las familias, el desplazamiento forzado, la violencia, la dispersión de la población, el trabajo infantil e, incluso, la no detección oportuna de la discapacidad auditiva.

Esta investigación se fundamenta en el modelo de Educación Bilingüe Bicultural para sordos (E.B.B.S.); además, reconoce a la LSC como su primera lengua, y tiene en cuenta la importancia del conocimiento y contacto con su segunda lengua, el castellano escrito. Asimismo, se apoya en las Tecnologías de la Información y la Comunicación (TIC), al ser reconocidas como recursos que se emplean en el ámbito pedagógico y pueden cumplir un papel indispensable para mejorar el proceso lector en estudiantes sordos. Lo anterior, considerando que la información presentada es flexible y se adapta a las necesidades de las personas. Según Zappalá y Suchodolski (2011), el desarrollo de proyectos que incorporen la tecnología facilita los procesos de enseñanza y de aprendizaje, y desarrollan capacidades y competencias al atender a la diversidad y a las características propias de los aprendices, pues propician la motivación para el logro de aprendizajes significativos.

Las herramientas tecnológicas mediadas por la internet facilitan la educación en todos los niveles de formación (García-Chitiva, 2020). La incorporación de las tecnologías ha cambiado la forma en la que los estudiantes acceden a la escritura y la lectura por la motivación que su uso genera (Hernández-Sánchez \& Santamarina-Sancho, 2016). Por lo anterior, la investigación basada en tecnología educativa puede dar respuesta a las necesidades educativas al recurrir a teorías y modelos basados en innovación e investigación (De Benito \& Salinas, 2016). Según Duque (2016), la incorporación de estrategias didácticas mediadas por tecnología puede favorecer la comprensión lectora en estudiantes con discapacidad auditiva. A partir de su experiencia, Duque diseñó un aula asistiva como una herramienta pedagógica que incluye el uso de objetos virtuales de aprendizaje (OVA), los cuales responden a las necesidades de la población sorda al mejorar los niveles de comprensión lectora y fomentar el interés por la lectura, lo que favorece, a su vez, la educación inclusiva.

La tecnología ofrece una amplia gama de opciones que pueden incorporarse en el ámbito educativo, dependiendo de las necesidades de los estudiantes, sus intereses, estilos de aprendizaje y propósitos educacionales. Tanto las tecnologías de apoyo como las aplicaciones en línea son útiles para las personas con discapacidad, ya que facilitan su independencia, autonomía y aprendizaje (Bravou \& Drigas, 2019); así, para el presente estudio se ha seleccionado el blog. Jou (2009) define el blog como una bitácora que favorece la interacción entre usuarios, en el cual se pueden incorporar elementos de multimedia, lo que permite diversas opciones para presentar los contenidos adaptándose a los distintos estilos de aprendizaje. Estas aplicaciones web son medios para el aprendizaje de la cultura y el intercambio intercultural; espacios de 
alfabetización que favorecen el desarrollo de la identidad y autonomía del estudiante (Reinhardt, 2019). Según Mutia et al. (2020), los medios de aprendizaje basados en un blog atraen el interés de los estudiantes por encima de los medios convencionales.

Los blogs educativos, también llamados edublogs, rompen barreras espaciales del contexto educativo tradicional, al generar entornos de aprendizaje que facilitan la interacción y el trabajo colaborativo (Lizandra et al., 2016). Asimismo, permiten la utilización de recursos multimedia, como el video, la imagen, la animación, entre otros. Estos medios digitales son versátiles, permiten ser transformados y pueden favorecer la comprensión lectora, al ofrecer al estudiante múltiples formas para interactuar con el contenido.

La aplicación de la tecnología en el ámbito de la educación es muy importante para mejorar la calidad y fomentar la justicia social en el ámbito educativo (Chairuddin, 2019), por lo tanto, es innegable la necesidad de aumentar la alfabetización digital y el uso de estrategias mediadas por tecnologías (Samani et al., 2020). Para el caso particular de la población sorda, la información se presenta haciendo énfasis en el canal visual, y se puede acompañar de contenidos en su lengua materna, es decir, la LSC. El blog puede convertirse en un recurso que en el ámbito educativo propicia el interés en el alumno debido a las aplicaciones que permite utilizar, su carácter interactivo y la presentación de la información acorde con el canal de aprendizaje preferente de la población del estudio (Mutia et al., 2020). Se destaca el uso del canal visual (imágenes, animaciones, videos, etc.), debido a esto, puede ser un medio apropiado para iniciar, enseñar y fortalecer el aprendizaje del castellano escrito en sordos. Es el estudiante quien decide cuáles son las actividades de mayor interés; además, puede ajustarlas a su tiempo de forma flexible. Para acceder al recurso solo requiere conexión a Internet y puede hacerlo desde un dispositivo móvil o computador. Lo anterior contribuye a que los estudiantes sean lectores autónomos y activos, que acceden al blog de manera ubicua, promoviendo habilidades cognitivas como la reflexión, análisis, deducción e inferencia, al favorecer la accesibilidad al conocimiento, su autonomía y metacognición. Un blog educativo integrado a un sistema de enseñanza optimiza el proceso y favorece las competencias comunicativas y tecnológicas (Prykhodko et al., 2019). Es así como el blog como recurso educativo favorece el intercambio de ideas y la redacción de textos. Igualmente, es un sitio web de fácil acceso, gratuito, sencillo de gestionar, crear y, a diferencia de la página web, propicia una mayor interacción entre los participantes.

\section{Método}

La ruta metodológica se enmarca en el paradigma histórico hermenéutico, que parte de la realidad para describir e interpretar el contexto social; se focaliza en las problemáticas que presentan los estudiantes sordos. Al respecto, Capocasale (2015) expresa que el interés se centra en concebir y analizar la realidad construida por los sujetos. De esta manera, bajo el enfoque cualitativo, se planteó el derrotero investigativo orientado, básicamente, en conocer los procesos lectores de nueve estudiantes sordos de noveno grado con extraedad (17-40 años) de una institución educativa distrital en la modalidad de validación. El contexto de investigación es una institución educativa pionera en bilingüismo para la población sorda en el departamento del Atlántico, al norte de Colombia, la cual implementa capacitaciones a docentes, directivos y padres de familia en LSC y cuenta con un amplio equipo interdisciplinario que incluye intérpretes y modelos lingüísticos (Clavijo, 2018).

Desde una perspectiva holística se desarrolló el acercamiento al objeto investigado, atendiendo los factores que confluyen ante el mismo, el desarrollo de los sujetos en su contexto natural y las interacciones que median en los procesos. Es así como los criterios para la recolección de la información privilegiaron el conocimiento del nivel del proceso lector de los participantes, las interacciones entre docente y estudiante, y las mediaciones que hay, como las metodologías, las estrategias de enseñanza y los recursos educativos. De esta manera, se optó por las siguientes técnicas e instrumentos de recolección de información, 
en coherencia con los objetivos planteados en este trabajo investigativo.

- Observación participante: técnica más adecuada para conocer "el hacer" de los sujetos sobre los cuales se investiga (Alonso, 1995). Se proyectó a las metodologías de enseñanza y estrategias pedagógicas que utilizan los docentes para promover el interés por la lectura en los estudiantes sordos. Asimismo, se referencian otros factores que convergen en la comprensión y motivación por la lectura.

- Diario de campo: herramienta indispensable para el registro de la información producto de la observación. Así lo precisa Gurdián (2007): “un registro detallado, preciso y completo de acontecimientos y acciones." (p. 192). Este instrumento permitió tener una visión más precisa sobre las características del grupo y sus interacciones.

- Entrevista estructurada: técnica que permite conocer el objeto investigado desde la perspectiva de estos -opiniones, creencias y percepcionesa través de cuestionarios estructurados, con preguntas, secuencias y formulaciones predeterminadas. Fueron orientadas a docentes y estudiantes sobre aspectos como los hábitos lectores, las estrategias de enseñanza y el uso de recursos educativos tecnológicos. Este último aspecto se centró principalmente en el uso del blog en el aula de clase y las posibilidades que ofrece en el proceso lector en personas que presentan algún tipo de discapacidad auditiva.

- Formato de entrevista: formulario de preguntas estructurado a partir de las categorías de investigación, que busca registrar información acerca de las concepciones y percepciones sobre las estrategias de enseñanzas, el proceso lector en estudiantes sordos y el uso de recursos tecnológicos. Se siguieron las recomendaciones de formular preguntas de lo general a lo particular, y de establecer un tipo de relaciones entre las mismas (Piza et al., 2019).

- Prueba de comprensión lectora: esta técnica permitió recolectar información específica del grado de dominio de la lectura que tienen los participantes. Este hallazgo permite ofrecer orientaciones sobre los procesos de enseñanza en la lectura. El instrumento utilizado en este estudio es el test de complejidad lingüística progresiva.

- Test CLP (complejidad lingüística progresiva): es un instrumento estandarizado diseñado por Alliende et al. (2004), el cual sirve para medir la capacidad de lectura y corresponde a los 8 niveles de educación o iniciación a la lectura. Utiliza textos elaborados especialmente para la prueba, controlando los aspectos semánticos, sintácticos y pragmáticos.

Posteriormente, para el análisis de la información, se desarrolló un proceso de triangulación, método que ofrece una mayor comprensión del objeto de estudio a través del uso de múltiples técnicas y de datos (Denzin, 1970). De esta manera, se procedió a la sistematización en unidades de análisis, para luego establecer un sistema de relaciones que permitió la categorización en agrupaciones que daban cuenta de los principales hallazgos en relación con el dominio de la primera lengua y la apropiación de la segunda lengua, es decir, el español escrito, con los procesos de aprendizaje de los participantes y los recursos educativos para desarrollar el proceso lector, tal y como se aprecia en la figura 1.

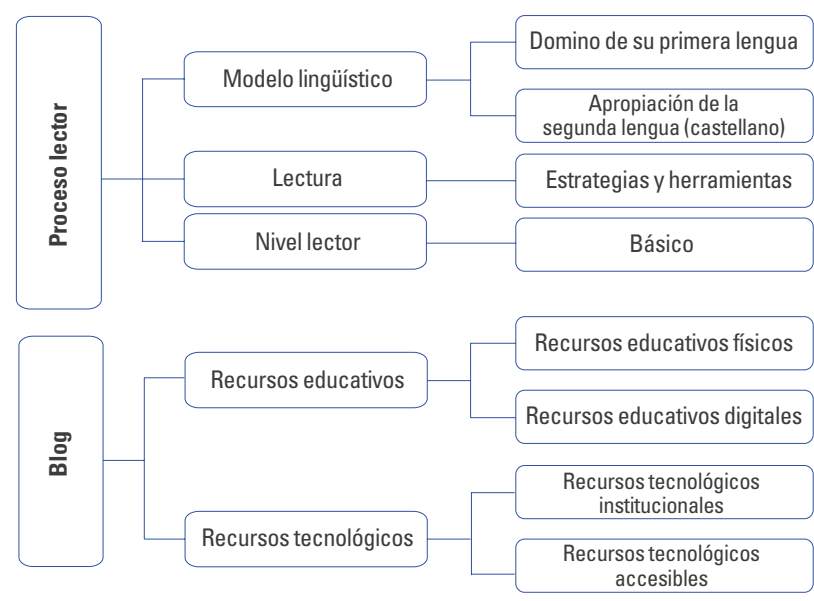

Figura 1. Categorización básica

Fuente: elaboración propia. 
Posteriormente, se dio paso a la estructuración mediante el desarrollo de la integración sistemática de las categorías, de acuerdo a los objetivos de investigación, para continuar con la contrastación que permite relacionar categorías o estructuras por semejanza o diferencia. Este proceso permitió el hallazgo de principios que, al relacionarse con los fundamentos teóricos, se convierten en los resultados presentados a continuación.

\section{Resultados}

Los resultados de la investigación se presentan inductivamente a partir del análisis individual de la información obtenida de las técnicas aplicadas. Luego se exponen los hallazgos globales, estructurados a partir de las categorías de base y emergentes. Más adelante, organizados en tres apartados, se muestran los resultados obtenidos durante el estudio, los cuales fueron considerados para la elaboración de una propuesta pedagógica pertinente y acorde con las necesidades identificadas.

\section{Observación registrada mediante diario de campo}

En la observación realizada durante las sesiones académicas llevadas a cabo por los docentes, se evidenció la existencia de una buena relación entre estos y los estudiantes sordos, pues cuentan con un clima de confianza; aunque en cierta medida, esta relación se ve limitada por el básico conocimiento que tienen los docentes de la LSC. Por otra parte, con respecto a la relación entre los alumnos sordos y oyentes, esta es adecuada: no existe segregación social de ninguna de las partes. Para el desarrollo de las actividades académicas, se cuenta con el servicio de interpretación en LSC, lo cual facilita la comunicación entre oyentes y sordos. El grupo se compone de 14 estudiantes: 5 estudiantes oyentes sin ninguna discapacidad asociada, y 9 estudiantes con discapacidad auditiva que tienen una edad comprendida entre los 17 y 40 años. Esto pone en evidencia que dentro del aula de clase hay más estudiantes con discapacidad auditiva que sin ninguna discapacidad, por lo que este grupo es muy significativo para abordar la problemática de los procesos lectores en los estudiantes sordos.

En cuanto a los estudiantes sordos, el dominio que tienen de su primera lengua es óptimo y manejan un amplio vocabulario en LSC; pero al referirse a su segunda lengua (el castellano escrito), su conocimiento es escaso, por lo que manejan un pobre vocabulario y se les dificulta entender oraciones complejas y el lenguaje figurativo, lo que disminuye su motivación frente a la lectura. Una de las estrategias que utilizan los docentes consiste en entregar material escrito para su lectura, el cual se acompaña posteriormente de un debate y formulación de preguntas sobre el texto. De igual forma, se observó que los docentes no promueven en los estudiantes sordos la lectura independiente, lo que se ve demostrado en la necesidad que tienen de que la lectura sea interpretada y en cierta manera explicada en LSC; como consecuencia, no se promueve la autonomía. Por último, no se evidenció el uso de herramientas tecnológicas que promuevan o incentiven los procesos académicos en los estudiantes, es decir, que no se había considerado el blog como una opción para el trabajo de comprensión lectora.

\section{Entrevista estructurada}

Las entrevistas fueron aplicadas a docentes y estudiantes de la institución educativa objeto de estudio. La entrevista dirigida a docentes evidenció que entre las adaptaciones curriculares más importantes se encuentran la comunicación (intérprete de LSC en el aula de clase), el acceso al currículo (la revisión y modificación de los elementos de la planificación, gestión y de evaluación que integra el currículo) y el acceso físico (buena iluminación en el aula de clase y ubicación preferencial del alumno). Se puede apreciar que las adaptaciones que los docentes consideran que más emplean son la de la comunicación (manifestada por dos docentes), seguida por la de currículo y 
físico (manifestada por una persona), por lo que dentro de la institución no existen barreras de comunicación, ya que se cuenta con un cuerpo de intérpretes con idoneidad que facilitan la comunicación de los oyentes con los estudiantes con discapacidad auditiva, así como el acceso a la información. Con expresiones como la siguiente, los profesores afirmaron que utilizan como recurso pedagógico materiales escritos y lo acompañan de recursos visuales:

D1: "Para mí es importante presentar los textos acompañados de imágenes, de esta forma puedo ayudarlo [al estudiante] a apoyarse en estas para mejorar su comprensión lectora".

En cuanto al uso de la tecnología, ninguno de los docentes manifestó emplear la tecnología como recurso pedagógico, a pesar de conocer la importancia y accesibilidad que les brindaría para atender a todas las necesidades de la población educativa, más aún, teniendo en cuenta que la institución cuenta con un aula de informática bien equipada con computadores portátiles en buen estado y con acceso a internet:

D2: "Sí tenemos un salón de informática, sin embargo, por problemas de logística lo usamos poco en otras clases diferentes a las de tecnología, pero ocasionalmente se les proyectan películas y videos".

Con respecto a las estrategias que utilizan los docentes para promover hábitos lectores en los estudiantes sordos, estos aseguraron que utilizan como estrategias recordar información esencial y subrayar ideas principales, así como estrategias para construir imágenes a partir de lo leído y establecer una relación entre lo que saben y no saben. Dentro de los tipos de texto más utilizados se encuentran los académicos, cuentos y fábulas. Todos los docentes manifestaron tener el objetivo de promover el interés por la lectura y generar hábitos lectores en los estudiantes.

D3: "Nuestros estudiantes necesitan mejorar su lectura y escritura; ese es un elemento clave para su comunicación con oyentes y para comprender gran parte de la información que reciben del medio".

Por su parte, los estudiantes sordos entrevistados consideraron que los hábitos lectores son útiles en todos los ámbitos de su vida cotidiana; además, manifestaron un posible interés por aprender y apropiarse de su segunda lengua. Asimismo, declararon leer por placer; sin embargo, ocasionalmente lo hacen por obligación para cumplir con alguna actividad académica o una necesidad.

E1: "A mí me gusta leer, pero me cuesta trabajo, sobre todo cuando el tema del libro no me parece interesante".

Es importante mencionar que los estudiantes expresaron que les interesan diversos tipos de textos, tales como textos de ficción y novelas, y, en menor proporción, textos de terror.

\section{Test de complejidad lingüística progresiva CLP}

La prueba fue aplicada con el apoyo del servicio de interpretación, con el fin de dar las instrucciones a los estudiantes. A pesar de que el test sugiere la presentación de ocho niveles, los estudiantes solo desarrollaron los tres primeros ítems, debido a que se presentaron dificultades reiteradas y fue necesario suspender.

En el primer nivel de esta prueba se comprueba el dominio inicial de la lectura en cuanto a palabras y oraciones simples. En el segundo nivel se evidencia el dominio de la comprensión de oraciones y, finalmente, en el tercer nivel se examina el dominio de la comprensión de párrafos a nivel de textos simples. Con respecto al rendimiento de los estudiantes en las tres pruebas aplicadas, se encontró que, en la primera prueba -que fue en la que mejor rendimiento tuvo el grupo de referencia-, se evidenció un dominio inicial de la lectura al punto de reconocer y asociar palabras y oraciones simples con su correspondiente significado. En la segunda prueba, hubo un rendimiento óptimo en el dominio de la comprensión de oraciones y reconocimiento de las afirmaciones de un texto simple. En la tercera prueba, se reflejó un bajo desempeño por dificultades en la comprensión de párrafos en textos simples, lo que quiere decir que a los estudiantes se les dificultó realizar inferencias de un texto y seguir instrucciones. 


\section{Hallazgos globales}

El dominio de la primera lengua que tienen los estudiantes es óptimo, y se demuestra en el manejo de un amplio vocabulario en LSC. Se logró establecer que uno de los factores que contribuye a esto es la labor de los modelos lingüísticos que se encuentran en la institución. Los modelos lingüísticos, como usuarios nativos de LSC, promueven la adquisición y uso social de la LSC en aprendices sordos y oyentes, lo que permite el acercamiento a la cultura sorda. No sucede lo mismo con el proceso de apropiación de la segunda lengua (el español escrito). Se evidencia una mínima cantidad de vocabulario y un alto grado de dificultad para la comprensión de oraciones complejas y el lenguaje figurativo.

En relación con la lectura en los procesos de aprendizaje, tanto docentes como estudiantes sordos lo consideran fundamental. A pesar de esto, los docentes centran sus actividades para el desarrollo del proceso lector por medio de lecturas en clases, subrayar ideas principales, formulación de preguntas literales y debates, por lo cual no se promueve la lectura independiente. Es así como la mayoría de los participantes de esta investigación se encuentran en un primer nivel lector; en un dominio inicial de la lectura, solo reconocen y asocian las palabras y oraciones simples con su correspondiente significado, a la vez que tienen dificultad en la comprensión de párrafos en textos simples.

Al respecto de los recursos educativos, se privilegia el uso de material escrito de lectura, más que de recursos digitales o tecnológicos, a pesar de que la institución cuenta con diversos recursos tecnológicos -sala de informática, portátiles y conectividad-, y con docentes con conocimiento y manejo de estos. Esta situación se convierte en un factor clave para la desmotivación y desinterés por la lectura que presentan los participantes de este estudio.

Los resultados muestran la necesidad de una propuesta de intervención educativa que pueda mejorar el desempeño en la lectura y generar motivación en el proceso lector de los participantes, así como el aprovechamiento de los recursos y el talento del personal con que cuenta la institución educativa.

\section{Propuesta pedagógica: blog "Un mundo lleno de letras"}

De acuerdo a los resultados obtenidos, y siguiendo experiencias como la de Herrera y Calderón (2019) y Duque (2016), se diseñó una propuesta pedagógica mediada por el blog como recurso educativo, teniendo en cuenta actividades y estrategias que consideran las características de estudiantes con discapacidad auditiva como aprendices visuales de una segunda lengua. Entre esas estrategias está realizar preguntas de inferencia, explicar las diferencias gramaticales de ambas lenguas -es decir, la LSC y el castellano escrito-, vincular imagen-seña-palabra, la lectura de palabras y pseudopalabras, la narración en LSC, asociar palabra-seña-dactilología, conectar información entre oraciones y párrafos (Duque, 2016; Herrera \& Calderón, 2019) y el apoyo en textos interpretados en videos con LSC. Estas actividades propuestas en el blog tienen como finalidad propiciar herramientas y estrategias que pueden ser utilizadas por los docentes que deseen dar continuidad al trabajo realizado en este sitio web. Las actividades plasmadas no fueron aplicadas a toda la población objeto de estudio, sino validadas a través de jueces expertos y pilotajes a dos estudiantes sordos con la misma edad de la población objeto de estudio.

Las habilidades y el interés por la lectura se desarrollan en ambientes pedagógicos estimulantes que incentiven al alumno a demostrar destrezas lectoras y capacidades cognitivas. Con base en los resultados hallados, para fomentar hábitos lectores en los estudiantes sordos se requieren espacios y materiales didácticos de carácter visual (apoyado en otros formatos multimedia) que brinden la oportunidad de enfrentarse a un texto escrito. Dentro de los aspectos que llevaron a la construcción del blog como recurso educativo, se consideró presentar material visual accesible como videos e imágenes en LSC, seleccionando su contenido de acuerdo a los intereses de los estudiantes sordos, principalmente en referencia a los tipos de textos y lecturas a trabajar.

El blog es un recurso educativo óptimo que puede adaptarse a las necesidades académicas de la 
población de estudiantes con discapacidad auditiva y que permite un acercamiento al mundo de la lectura. Esta aplicación web fue seleccionada considerando su carácter interactivo, lo que la diferencia de una página web. En un blog educativo, la comunicación entre docente y estudiante puede darse por aplicaciones integradas mediante gadgets y comentarios (Prykhodko, 2019). Para el diseño del blog se tuvieron en cuenta contenido, diseño original, comodidad de navegación por pestañas y menús, interactividad y retroalimentación (Kazhan et al., 2020), así como aspectos relacionados con la accesibilidad y alternativas visuales en LSC.

El blog se dividió en secciones de acuerdo a su nivel de complejidad. Cada sección cuenta con actividades que tienen como propósito fortalecer e incentivar destrezas lectoras en los estudiantes sordos, al igual que brindar una experiencia pedagógica más interactiva con explicaciones e instrucciones en LSC (véase figura 2).

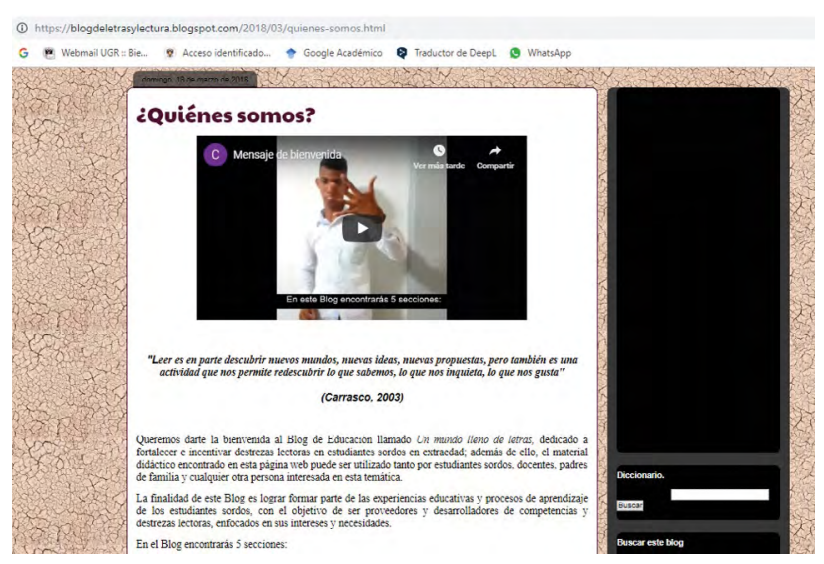

Figura 2. Blog "Un mundo lleno de letras"

Fuente: blog "Un mundo lleno de letras".

Se diseñaron e insertaron actividades realizadas desde sitios web como Educaplay, videos, hipervínculos y documentos en PDF, imágenes y presentaciones en diapositivas (véase figura 3). Es importante mencionar que Educaplay es una plataforma para crear contenidos y actividades multimedia que ha sido utilizada para desarrollar planes de intervención en estudiantes con necesidades de apoyo educativo. Su carácter interactivo favorece la participación de los estudiantes y la generación de entornos de enseñanza flexibles (Salazar et al., 2019).

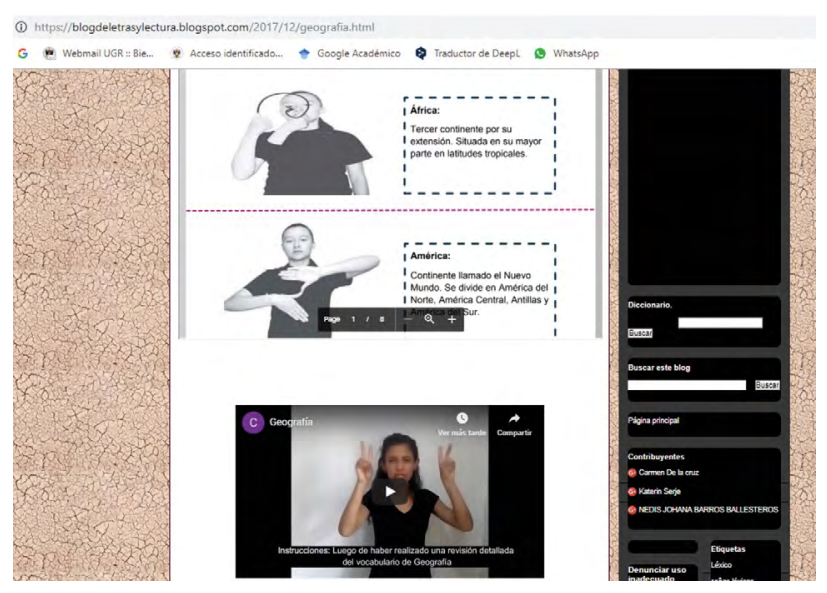

Figura 3. Diferentes recursos del blog

Fuente: blog "Un mundo lleno de letras".

Estos recursos educativos tecnológicos son indispensables para crear un ambiente de aprendizaje más dinámico e interactivo, en el cual el estudiante se divierta aprendiendo y pueda fortalecer los procesos lectores que se han visto obstaculizados por el poco conocimiento de su segunda lengua y sus escasos hábitos lectores. El estudiante puede trabajar de forma autónoma o con apoyo de un intérprete, docente y modelo lingüístico que lo oriente en el desarrollo de los ejercicios de lectura implementados en este sitio web, teniendo en cuenta que la herramienta Educaplay es un aporte valioso para los estudiantes que presentan dificultades en el desarrollo de sus habilidades comunicativas lectoras (Páez \& Mercado, 2021).

Para su diseño, se consideraron los criterios de navegación, contenido, diseño tecnopedagógico y multimedia. El blog "Un mundo lleno de letras" es un espacio educativo que tiene como objetivo apoyar los procesos lectores en estudiantes con discapacidad auditiva en extraedad, diseñado de tal manera que sea fácil de utilizar y que, a través de sus contenidos apoyados con videos en LSC e imágenes, puedan ser comprendidos por la población a la que va dirigido, favoreciendo de esta forma la educación inclusiva. Esta herramienta o recurso educativo favorece la 
educación inclusiva de estudiantes con discapacidad auditiva; además, genera un elemento de motivación e interés por la lectura. El material pedagógico encontrado en el edublog puede ser utilizado por la comunidad en general, ya que se dispuso como un recurso educativo abierto.

La propuesta educativa se sometió a validación por tres jueces expertos. Este es un método de validación útil para verificar la fiabilidad de una investigación, instrumento o, en este caso, propuesta pedagógica. Según Escobar-Pérez y Cuervo-Martínez (2008), una validación por jueces expertos es una opinión informada de personas con trayectoria en el tema, quienes pueden emitir opiniones, juicios y valoraciones. Para el caso particular del presente estudio, se contó con la participación de dos magísteres con experiencia en el modelo bilingüe bicultural para sordos, uno de ellos intérprete de LSC, así como un modelo lingüístico con formación y experiencia en el sector educativo. Los resultados revelaron que los criterios de alcance pedagógico, relación del contenido, efectividad, comunicación, navegación, gráfica y multimedia fueron valoradas con un promedio de 4 en una escala de 0-5.

De acuerdo a la prueba piloto realizada, se observaron resultados positivos sobre los criterios de evaluación establecidos: "navegación”, "contenido" y "diseño y multimedia". Esto puede interpretarse como una experiencia satisfactoria que logra alcanzar los objetivos propuestos; los estudiantes no presentaron dificultad al momento de interactuar con el blog y su contenido, sin embargo, se sugirió suministrar más apoyos visuales como imágenes y videos adaptados en lengua de señas para una mayor comprensión del contenido de la página web. Luego de la valoración por jueces y prueba piloto se analizaron las sugerencias de mejora, las cuales fueron tenidas en cuenta como una versión 2.0 del blog. Es importante mencionar que el blog fue puesto a disposición de la comunidad educativa objeto de estudio y su cuerpo administrativo y docente, con el fin de que este sea implementado y se valore su aplicación, determinando las posibles mejoras e impacto que su uso pueda generar en las habilidades lectoras de los estudiantes.

\section{Discusión}

Las dificultades en la comprensión lectora pueden generar consecuencias en el acceso a las experiencias de la vida cotidiana, así como limitaciones de grado variable en el desarrollo cognitivo (Carrero, 2017). Al ser la comprensión lectora una reinterpretación significativa y personal de los textos escritos, se justifica en la medida que el lector es capaz de darle sentido a los significados (Almeida, 2012). Así, este proceso es fundamental para la inclusión educativa y social.

A partir de la problemática planteada sobre las dificultades que presentan los estudiantes sordos en cuanto a la compresión de texto, se diseñó un blog como recurso educativo para fortalecer el proceso lector, siendo este de vital importancia para darle a conocer a los docentes cómo su utilización puede favorecer el desarrollo y mejora de la lectura y habilidades cognitivas en los estudiantes. Arnaiz y Azorín (2012) afirman que los blogs y su versión educativa, los edublog, evolucionan hacia un aprendizaje activo que resignifica la forma de aprender. Una enseñanza adecuada debe tener en cuenta recursos educativos que sean innovadores y motivadores, que valoren el ritmo de aprendizaje de los estudiantes, sus intereses y necesidades, lo cual puede favorecer el desarrollo de sus potenciales y capacidades, más aún si permite la incorporación de múltiples formatos, como lo son el texto, video, animación e imágenes. Incorporar recursos visuales proporciona un aprendizaje mejor y permanente en comparación con el uso exclusivo de la instrucción en lengua de señas, si se considera que los estudiantes aprenden y recuerdan mejor cuando se les presentan nuevos elementos de vocabulario (Gülengül-Birinci \& Sariçoban, 2021).

La visualidad y gestualidad de la LSC son elementos constitutivos del bilingüismo e identidad de sordos, por lo tanto, son fundamentales para su desarrollo socioafectivo y académico (Herrera \& Calderón, 2019). El objetivo de los blogs educativos es apoyar el proceso de enseñanza-aprendizaje en un contexto educativo; su potencial revoluciona la estructura tradicional de la enseñanza, y su carácter gratuito facilita su 
integración (Lara, 2005; Marcos et al., 2013; Lizandra et al., 2016). Los blogs han mediado espacios de comunicación, por medio de los cuales los sordos expresan sus emociones, entre ellas lo que les genera la problemática de accesibilidad de los contenidos digitales y las reclamaciones sobre el reconocimiento de su lengua materna (Castillo et al., 2019).

Atender a la diversidad y variación lingüística de estudiantes sordos es considerar el desarrollo de propuestas pedagógicas flexibles que partan de sus necesidades e intereses, al mismo tiempo que propongan formas de diseño, desarrollo y seguimiento de las actividades que fomenten la implicación y motivación de aquellos (Carrero, 2017). Las estrategias pedagógicas utilizadas por los docentes pueden ser tradicionales, reproduciendo modelos y didácticas que se emplean con estudiantes oyentes, por lo tanto, es necesaria la cualificación del profesorado para afrontar las demandas del proceso educativo de los sordos (Herrera \& Calderón, 2019; Gülengül-Birinci \& Sariçoban, 2021)

El blog como recurso educativo contribuye al desarrollo de las capacidades y habilidades en las personas; además, es una herramienta que despierta interés en los estudiantes sordos, debido a que la información que se muestra es de carácter visual y favorece la comprensión de la información que se presenta en su segunda lengua - apoyada a la par en su lengua materna-, fomentando el desarrollo de las competencias lingüísticas. Se tuvo en cuenta el componente lector, enfocado en promover la motivación por la lectura en el estudiante, comprender la estructura de un texto y abstracción de ideas principales y palabras clave, las cuales son importantes para una adecuada lectura (Alegría et al., 2009), así como la estimulación de conocimientos previos (Martínez, 2021). Se aprovecharon plataformas tipo herramientas de autor, las cuales permiten la incorporación de elementos de gamificación, como por ejemplo actividades interactivas desarrolladas en la plataforma Educaplay, la cual ha sido empleada para trabajar con estudiantes con necesidades específicas de apoyo educativo (Salazar et al., 2019). Lo que se pretendió con la elaboración de este proyecto es que los estudiantes sordos tuviesen suficiente motivación por la lectura, hacer de ellos lectores habituales y mejorar su nivel de competencias lectoras, al ser estas necesarias para interactuar con información escrita y comunicarse con personas oyentes, uno de los reajustes sociales que requieren los sordos usuarios de lengua de señas para ser incluidos es la innovación en las prácticas pedagógicas desde el bilingüismo y la interculturalidad (Herrera \& Calderón, 2019).

\section{Conclusiones y recomendaciones}

En el caso de estudiantes sordos y en condición de extraedad, es importante reconocer el doble riesgo de exclusión latente; por ello, es fundamental favorecer condiciones académicas particulares y fomentar su participación activa (Carrero, 2017). En ese orden de ideas, es necesario identificar las necesidades que presentan en cuanto a la comprensión lectora, y diseñar estrategias pedagógicas que involucren el uso de la LSC. Las habilidades y el interés por la lectura se dan cuando existen ambientes pedagógicos estimulantes que incentiven al estudiante a desarrollar destrezas lectoras y capacidades cognitivas. Por lo anterior, es muy importante brindar todas las herramientas y recursos educativos necesarios que estimulen el desarrollo de habilidades lectoras.

Con base en los resultados hallados, para fomentar hábitos lectores en los estudiantes sordos se requieren espacios y materiales didácticos en diferentes formatos, y el blog se convierte un recurso educativo óptimo que se adapta a las necesidades académicas de la población de estudiantes con discapacidad auditiva, ya que permite un acercamiento al mundo de la lectura por medio del uso de materiales multimedia.

Según Jou (2009), el blog es un recurso educativo que posibilita crear materiales pedagógicos a través de presentaciones en multimedia. Los recursos tecnológicos son herramientas que, si se implementan adecuadamente, se adaptan al estilo de aprendizaje de los estudiantes con discapacidad auditiva a través de recursos digitales y pueden ser ideales para fortalecer el aprendizaje del castellano escrito. Este estudio hace énfasis en la incorporación de recursos educativos

CIEncia y Poder AÉreo | vol. 16 n. ${ }^{\circ} 2$ | julio-diciembre del 2021 | pp. 148-162 | ISSN 1909-7050 E-ISSN 2389-9468 | https://doi.org/10.18667/cienciaypoderaereo.718 
tecnológicos para estimular el proceso lector en los estudiantes sordos. Se llega a la conclusión de que el uso de las TIC en el aula de clase es importante para crear ambientes pedagógicos incluyentes que valoren los estilos y ritmos de aprendizaje propios de los estudiantes con discapacidad auditiva.

Se recomienda a los docentes optimizar las adaptaciones educativas manejadas durante las actividades con estudiantes que presentan discapacidad auditiva, implementando en todas estas actividades un apoyo visual -incluyendo el uso de la tecnología educativa que favorezca la presentación de la información-y considerando la importancia de este sentido como apoyo en la educación de los estudiantes. Es importante familiarizar a los estudiantes con múltiples formatos para generar un hábito lector y una apropiación por la lectura.

Teniendo en cuenta que es importante validar la propuesta pedagógica con el uso y aplicación, se recomienda utilizar el blog como recurso tecnológico y pedagógico con estudiantes sordos, al igual que el aprovechamiento de las actividades propuestas, las cuales tienen apoyos de videos en LSC, textos adaptados con palabras clave que manejan un vínculo guiado hacia la seña que le corresponde o un sinónimo que permita el aprendizaje de palabras nuevas. Todo lo anterior estimulará el proceso lector.

Declaración de conflicto de interés: Los autores no manifiestan conflictos de interés institucionales ni personales.

\section{Referencias}

Al-Ibrahim, A. (2019). Deaf and Hard of Hearing Students' Perceptions of the Flipped Classroom Strategy in an Undergraduate Education Course. European Journal of Educational Research, 8(1), 325-336. https://doi: 10.129 73/eu-jer.8.1.325

Alegría, J., Domínguez, A., \& Van der Straten, P. (2009). ¿Cómo leen los sordos adultos? La estrategia de palabras clave. Revista de Logopedia, Foniatría y Audiología, 29(3), 195206. https://doi.org/10.1016/S0214-4603(09)70028-2
Almeida, A. (2012). La evaluación de la comprensión lectora como práctica docente. Ciencia y Poder Aéreo, 7(1), 6873. https://doi.org/10.18667/cienciaypoderaereo.22

Alliende, F., Condemarín, M., \& Milicic, N. (2004). Prueba CLP formas paralelas. Manual para la aplicación de la prueba de comprensión lectora de complejidad lingüística progresiva: 8 niveles de lectura. Ediciones Universidad Católica de Chile.

Alonso, L. E. (1995). "Sujeto y discurso: el lugar de la entrevista en las prácticas de la sociología cualitativa”. En J. M. Delgado \& J. Gutiérrez (Coords.), Métodos y técnicas cualitativas de investigación en ciencias sociales. Síntesis.

Arnaiz, P., \& Azorín, C. (2012). El edublog como herramienta de aprendizaje para todos en el entorno virtual. Didáctica, innovación y multimedia, (24), 1-12. https://raco.cat/in dex.php/DIM/article/view/269826

Augusto, J., \& De Antoñana, R. (2002). La lectura en los niños sordos: el papel de la codificación fonológica. Anales de psicología, 18(1), 183-195. https://revistas.um.es/ analesps/article/view/28691

Bravou, V., \& Drigas, A. (2019). A Contemporary View on Online and Web Tools for Students with Sensory \& Learning Disabilities. International Journal of Online and Biomedical Engineering, 15(12), 97-105. https://doi.org/10.3991/ ijoe.v15i12.10833

Capocasale, A. (2015). ¿Cuáles son las bases epistemológicas de la investigación educativa? En L. Abero, L. Berardi, A. Capocasale, S. García, R. Rojas \& O. Barboza (Eds.), Investigación educativa. Abriendo puertas al conocimiento (pp. 32-47). CLACSO.

Carrero, F. (2017). La comprensión lectora en el alumnado sordo desde la perspectiva de la Escuela Inclusiva. International Journal of Educational Research and Innovation (IJERI), 8, 200-219. https://www.upo.es/revistas/index. php/IJERI/article/view/2360

Castillo, A., Sánchez-Gómez, M., \& Costa, A. (2019). Autodeterminación, emociones y exclusión en un blog de personas sordas: mirada cualitativa. Revista Brasileira de Enfermagem, 72(4), 1.094-1.101. http://dx.doi. org/10.1590/0034-7167-2018-0573

Chairuddin, C. (2019). E-Learning (Edublogs) Social Media Based: Its Implementation in Teaching Learning at Islamic Senior High School Bangkalan. Jurnal Pengabdian Masyarakat Khatulistiwa, 2(2), 46-50. https://doi. org/10.31932/jpmk.v2i2.543 
Clavijo, J. (2018). Política pública colombiana para la educación de niños sordos. En C. Correa, E. Sepúlveda, M. Domínguez \& R. Fontalvo (Comps.), La inclusión: una base para la educación. Ediciones Universidad Simón Bolívar.

De Benito, B., \& Salinas, J. (2016). La investigación basada en diseño en Tecnología Educativa. Revista Interuniversitaria de Investigación en Tecnología Educativa, 0, 44-59. https://doi.org/10.6018/riite2016/260631

Denzin, N. K. (1970). The Research Act: A Theoretical Introduction to Sociological Methods. Transaction Publishers.

Duque, L. (2016). Fortalecimiento del proceso de inclusión de los escolares con discapacidad auditiva del colegio Isabel II [Trabajo de maestría, Universidad Libre]. Archivo digital Universidad Libre.

Escobar-Pérez, J., \& Cuervo-Martínez, Á. (2008). Validez de contenido y juicio de expertos: una aproximación a su utilización. Avances en medición, 6(1), 27-36. https://www. humanas.unal.edu.co/lab_psicometria/revista-avan ces-en-medicion/avances-en-medicion-no6

García-Chitiva, M. (2020). Mediación virtual en la enseñanza y la instrucción: avances y retos. Ciencia y Poder Aéreo, 15(1), 161-177. https://doi.org/10.18667/cienciay poderaereo.645

González, V., \& Domínguez, A. (2019). Lectura, ortografía y habilidades fonológicas de estudiantes sordos con y sin implante coclear. Revista de Logopedia, Foniatría y Audiología, 39(2), 75-85. https://doi.org/10.1016/j.rlfa.20 18.07.001

Greene-Woods, A., \& Delgado, N. (2020). Addressing the Big Picture: Deaf Children and Reading Assessments. Psychology in the Schools, 57(3), 394-401. https://doi. org/10.1002/pits.22285

Gülengül-Birinci, F., \& Sariçoban, A. (2021). The Effectiveness of Visual Materials in Teaching Vocabulary to Deaf Students of EFL. Journal of Language and Linguistic Studies, 17(1). https://doi.org/10.52462/jlls.43

Gurdián, A. (2007). El paradigma cualitativo en la investigación socioeducativa. Investigación y desarrollo.

Hernández-Sánchez, A., \& Santamarina-Sancho, M. (2016). El uso del texto enriquecido para la mejora de la comprensión lectora en el alumnado sordo.Etic@ net.Revista científica electrónica de Educación y Comunicación en la Sociedad del Conocimiento, 16(2), 371-386. http://dx.doi. org/10.30827/eticanet.v16i2.11930
Herrera, V., \& Calderón, V. (2019). Prácticas pedagógicas y transformaciones sociales. Interculturalidad y bilingüismo en la educación de Sordos. Revista latinoamericana de educación inclusiva, 13(1), 73-88. http://dx.doi. org/10.4067/S0718-73782019000100073

INSOR (2015). Boletín territorial. http://www.insor.gov.co/obser vatorio/download/boletin_territorial/ATLANTICO_DF.pdf.

INSOR (2019). Información sobre la población sorda colombiana. http://www.insor.gov.co/bides/documentos/

Jou, B. (2009). Blogs, ¿para qué? Marco ELE. Revista de Didáctica Español Lengua Extranjera, (8), 1-12. https://marco ele.com/blogs-para-que/

Kazhan, Y. M., Hamaniuk, V. A., Amelina, S. M., Tarasenko, R. O., \& Tolmachev, S. T. (2020). The Use of Mobile Applications and Web 2.0 Interactive Tools for Students' German-Language Lexical Competence Improvement. CEUR Workshop Proceedings, 2643, 392-415.

Lara, T. (2005). Blogs para educar. Usos de los blogs en una pedagogía constructivista, pedagogía con y sobre los weblogs. Telos, 65(2), 86-93. https://cutt.ly/pnKLIGg

Lizandra, J., Atienza, R., \& Gómez, F. (2016). Trabajar en la 'blogósfera': estudio de las percepciones del alumnado en la creación de una red de blogs colaborativos. EDUCADI, 1(1), 25-40. http://repositoriodigital.uctemuco.cl/ handle/10925/2210

Marcos, L., Pérez, C., \& Rodríguez, E. (2013). El blog como recurso educativo. Fundación Salamanca. https://www.ciu daddesaberes.es/guias/guiaBLOGS2.pdf

Martínez, C. (2021). Análisis de las estrategias semánticas de comprensión lectora de estudiantes sordos de nivel primaria del CAM N 5 de Tetecala Morelos [Trabajo de Grado, Universidad Autónoma del Estado de Morelos]. Archivo digital Universidad Autónoma del Estado de Morelos.

MEN. (s. f.). Extraedad. Glosario Ministerio de Educación Nacional. Ministerio de Educación Nacional. https://www. mineducacion.gov.co/1759/w3-propertyvalue-55247. html?_noredirect=1

Mendoza, E., \& Jackson-Maldonado, D. (2020). Lectura de palabras por personas sordas usuarias de lengua de señas mexicana. Revista de Logopedia, Foniatría y Audiología, 40(1), 4-11. https://doi.org/10.1016/j.rlfa.2019.05.003

Mutia, L., Gimin, G., \& Mahdum, M. (2020). Development of Blog-Based Audio Visual Learning Media to Improve Student Learning Interests in Money and Banking Topic. 
Journal of Educational Sciences, 4(2), 436-448. https:// doi.org/10.31258/jes.4.2.p.436-448

Páez, L., \& Mercado, E. (2021). Fortalecimiento de la lectura comprensiva mediante el recurso educativo digital Educaplay en segundo grado de la Institución Educativa Distrital Camilo Torres de Barranquilla [Trabajo de maestría, Universidad de Cartagena]. Archivo digital Universidad de Cartagena.

Piza, N., Amaiquema, F., \& Beltrán, G. (2019). Métodos y técnicas en la investigación cualitativa. Algunas precisiones necesarias. Conrado, 15(70), 455-459. http://scielo.sld. cu/scielo.php?pid=S1990-86442019000500455\&scrip $\mathrm{t}=\mathrm{sci}$ _arttext\&tlng=pt

Prykhodko, A. M., Rezvan, O. O., Volkova, N. P., \& Tolmachev, S. T. (2019). Use of Web 2.0 Technology Tool - Educational Blog - in the System of Foreign Language Teaching. En A. E. Kiv \& V. N. Soloviev (Eds.), Proceedings of the 6th Workshop on Cloud Technologies in Education (CTE 2018) (pp. 256-265). CEUR-WS.org.
Reinhardt, J. (2019). Social Media in Second and Foreign Language Teaching and Learning: Blogs, Wikis, and Social Networking. Language Teaching, 52(1), 1-39. https// doi:10.1017/S0261444818000356

Salazar, L. S., Pérez, H. G., \& Montes, L. P. (2019). The Educaplay Interactive Platform for the Learning of Mathematics in Populations with Special Educational Needs. En Journal of Physics: Conference Series, Cúcuta, Colombia (pp. 1-6). https://iopscience.iop.org/issue/1742-6596/1329/1

Samani, E., Bagheripour, R., \& Noordin, N. (2020). Effect of a Course on Educational Tools on Students' Attitude and Digital Literacy Skills. International Journal of Educational Technology and Learning, 8(1), 38-46. https://doi. org/10.20448/2003.81.38.46

Zappalá, D., Koppel, A., \& Suchodolski, M. (2011). Inclusión de TIC en escuelas para alumnos sordos. Ministerio de educación. 